\title{
Viability of Long-Lived Fission Products as Signatures in Forensic Radiochemistry
}

\author{
J.E. McAninch \\ I.D. Proctor \\ N.J. Stoyer \\ K.J. Moody
}

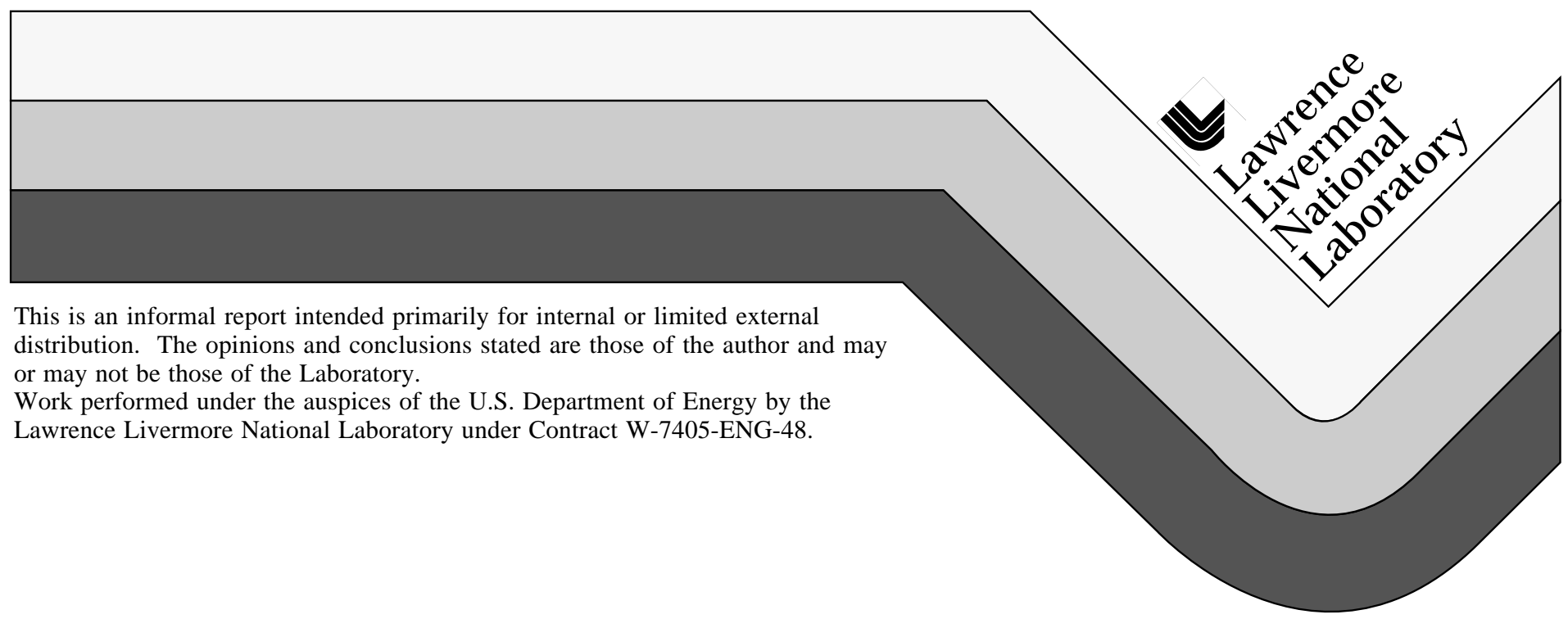




\section{DISCLAIMER}

This document was prepared as an account of work sponsored by an agency of the United States Government. Neither the United States Government nor the University of California nor any of their employees, makes any warranty, express or implied, or assumes any legal liability or responsibility for the accuracy, completeness, or usefulness of any information, apparatus, product, or process disclosed, or represents that its use would not infringe privately owned rights. Reference herein to any specific commercial product, process, or service by trade name, trademark, manufacturer, or otherwise, does not necessarily constitute or imply its endorsement, recommendation, or favoring by the United States Government or the University of California. The views and opinions of authors expressed herein do not necessarily state or reflect those of the United States Government or the University of California, and shall not be used for advertising or product endorsement purposes.

This report has been reproduced directly from the best available copy.

Available to DOE and DOE contractors from the Office of Scientific and Technical Information

P.O. Box 62, Oak Ridge, TN 37831

Prices available from (615) 576-8401, FTS 626-8401

Available to the public from the

National Technical Information Service

U.S. Department of Commerce 5285 Port Royal Rd.,

Springfield, VA 22161 


\title{
Viability of long-lived fission products as signatures in forensic radiochem istry
}

\author{
Jeffrey E. McAninch and Ivan D. Proctor
}

Center for Accelerator Mass Spectrometry, Lawrence Livermore National Laboratory

Nancy J. Stoyer and Kenton J. Moody

Isotope Sciences Division, Lawrence Livermore National Laboratory

January, 1997

\section{IN TRODUCTION}

The Isotope Sciences Division and the Forensic Science Center of the Lawrence Livermore National Laboratory are developing the discipline of Forensic Radiochemistry as a tool for determining information about the production and history of special nuclear materials for use in non-proliferation and anti-smuggling efforts. ${ }^{1,2}$ New and developing capabilities at the Center for Accelerator Mass Spectrometry at LLNL have the potential to aid this effort by allowing the detection of previously inaccessible long-lived radionuclides, including a number of long-lived fission products. ${ }^{3}$ The purpose of this paper is to open a discussion of the viability of these radionuclides as signatures for Forensic Radiochemistry, and to identify those isotopes with the highest potential as signatures, which will allow CAMS researchers to target their development efforts.

In particular, AMS has the potential to measure the three long-lived fission products ${ }^{90} \mathrm{Sr},{ }^{93} \mathrm{Zr}$ and

${ }^{99} \mathrm{Tc}$ in weapons grade $\mathrm{Pu}$ at the baseline levels generated by spontaneous fission. Contaminant levels of these isotopes remaining after fuel reprocessing are expected to be significantly elevated above these baseline levels, providing a measurable signal, but still well below detection limits for decay counting. The potential also exists to measure $\mathrm{U}$ and $\mathrm{Pu}$ isotope ratios with a wide dynamic range, including very low-level ${ }^{233} \mathrm{U} /{ }^{238} \mathrm{U}$ ratios. Measurement of these isotopes in seized material would provide additional information to assist the forensic examination.

\section{FOREN SIC RADIOCHEMISTRY}

The focus of the Forensic Radiochemistry efforts in the Isotope Sciences Division is to provide capabilities for the radiochemical analysis of special nuclear materials, as well as a database of "fingerprints" based on these analyses which are indicative of plausible sample scenarios. Because of the complexity and number of plausible sample compositions and histories, fingerprints are based on a relatively large suite of analytical signatures. Applied to a sample of seized material, the radiochemical analyses and subsequent interpretation can be combined with other forensic and investigative information to allow conclusions to be drawn about the point of origin and subsequent 
history of the sample.

The technical foundations for these efforts are measurements of chemical, elemental, stable isotope, and radionuclide compositions in nuclear materials. These measurements provide clues to the source material, irradiation history, and reprocessing or other treatment steps to which the material has been subjected, including the timing of these events. Many of the radionuclide signatures require the measurement of very small amounts of radioactive contaminants in the sample. Analytical techniques which improve the sensitivity, precision, or timeliness of these measurements or which open new isotopes to detection will expand and improve the suite of signatures.

Researchers at Isotopes Sciences have already made significant progress developing their methods. These methods involve the dissolution of matrix material (e.g. uranium or plutonium) followed by the selective extraction and purification of individual signatures. ${ }^{1,2}$ These signatures include uranium and plutonium isotopic composition, isotopic composition of other heavy elements in the alpha decay chains, and radioactive fission products with a wide range of half-lives. A variety of analytical techniques are then used to quantify these signatures including alpha, gamma, and beta counting as well as mass spectrometric techniques. They have successfully applied these methods to determine signatures whose concentrations in plutonium vary over sixteen orders of magnitude.

\section{LONG-LIVED FISSION PRODUCTS}

Fission products are inherently present in special nuclear materials as contaminants remaining from isotope separation or reprocessing, or through ingrowth due to spontaneous and neutron induced fission. The production of weapons-grade plutonium is accompanied unavoidably by the generation of fission products. To maximize the plutonium yield in reprocessing, small amounts of these undesirable contaminants often remain in the final product and can serve as indicators of the reprocessing chemistry (as an example, ${ }^{93} \mathrm{Zr}$ was a characteristic contaminant of the Hanford Redox method). Following reprocessing, the plutonium will undergo spontaneous fission, leading to a linear ingrowth of long-lived fission products(see Table 1). Exposure to significant neutron fluences will induce additional fission.

Analytically, the long-lived fission products represent attractive signatures. Natural abundances of the long-lived isotopes are extremely low. A small number of atoms can therefore represent a large signal. High precision isotope ratios are generally not required either, since one is not looking for small changes in a large ambient background ratio. Because the long-lived isotopes are essentially "stable" on the scale of years or decades, they provide a signal which does not reach saturation and does not need to be corrected for decay. Coupled with measurements of shorter-lived nuclides (0.1-100 y), the long-lived isotopes can also be used as the basis for "clocks" by establishing the initial activities of the shorter-lived species.

The long-lived fission products also offer a unique potential to extract spectral information about 
counting measurements of these isotopes.

\section{ACCELERATOR MASS SPECTROMETRY}

Accelerator mass spectrometry is an ideal analytical technique for use in Forensic Radiochemistry. AMS has high detection sensitivity, high specificity, and rapid turnaround. Unlike decay counting measurements, AMS measurements are based on atom counting and are independent of the half-life, type, or energy of the decay. The high specificity of AMS allows measurements to be made which are insensitive to activities from other radioisotopes in the sample. AMS measurements are rapid turnaround time is determined by sample preparation which generally requires only a few hours depending on the isotope and sample.

For most long-lived radioisotopes, the major limitation to detection by accelerator mass spectrometry is the presence of stable atomic isobars, i.e., non-radioactive isotopes of other elements which are of the same mass as the isotope of interest. Being of the same mass, these isobaric ions are not rejected by the spectrometer. For example, in the case of ${ }^{93} \mathrm{Zr}$, there will necessarily be a background from the stable isotope ${ }^{93} \mathrm{Nb}$. Most other mass spectrometric techniques are also susceptible to stable atomic isobars as well as interferences from molecular isobars.

A major advantage of AMS is the very high energy to which the ions are accelerated - typically tens of $\mathrm{MeV}$. This allows the use of nuclear physics-type particle detection and identification to be used for the post-spectrometer rejection of atomic isobars. For the fission products of interest here, CAMS researchers have recently worked to develop the use of characteristic projectile x-rays (PXAMS) for particle identification and isobar rejection. ${ }^{3}$ They have successfully applied the PXAMS technique to the low-level detection of ${ }^{59} \mathrm{Ni}$ and ${ }^{63} \mathrm{Ni}$, which were previously inaccessible at CAMS. ${ }^{5}$

Of the long-lived fission products listed in Table 1, CAMS presently has a capability to detect only

${ }^{129} \mathrm{I} .{ }^{4}$ In this special case, the only stable atomic isobar is ${ }^{129} \mathrm{Xe}$, which does not form a negative ion and therefore does not represent a background.

CAMS researchers are currently developing capabilities for the detection of ${ }^{99} \mathrm{Tc}$, and are planning to develop ${ }^{93} \mathrm{Zr}$ and ${ }^{90} \mathrm{Sr}$. Besides non-proliferation applications, it is planned to use these isotopes, which exist in the environment as radioactive fallout, as tracers in hydrology. These isotopes are also interesting in radioactive waste characterization and long-term storage. The determination of ${ }^{93} \mathrm{Zr}$ in nuclear weapon post-explosion debris would also be interesting to the Stockpile Stewardship program.

Preliminary results for ${ }^{99} \mathrm{Tc}$ indicate that a sensitivity $\sim 10^{7}-10^{8}$ atoms should be attainable. This is similar to the levels quoted in Ref. 2 (see Table 1) which are expected in $1 \mathrm{~g}$ of weapons grade Pu after 1 $\mathrm{y}$ of ingrowth from spontaneous fission. AMS detection of ${ }^{90} \mathrm{Sr}$ has been successfully developed by $\mathrm{M}$. Paul and collaborators at the Racah Institute of Physics at Hebrew University. ${ }^{6}$ A sensitivity $\sim 10^{7}$ 
atoms was achieved.

Measurements of very low ${ }^{233} \mathrm{U} /{ }^{238} \mathrm{U}$ ratios in special nuclear materials would also be beneficial to the Forensic Radiochemistry efforts at LLNL. CAMS is currently in the process of designing and installing a heavy element beamline for the detection of heavier isotopes, which should allow the measurement of ${ }^{233} \mathrm{U} /{ }^{238} \mathrm{U}$ ratios with the necessary abundance sensitivity.

\section{SUMMARY}

AMS measurement of long-lived fission products and uranium and plutonium isotopes has the potential to significantly aid the field of Forensic Radiochemistry by providing new or more sensitive signatures and improving on the speed with which they can be determined. Expanding the suite of signatures obtainable from an illicit sample of special nuclear material increases the likelihood that its point of origin can be positively identified, leveraging LLNL's impact on policy decisions regarding national security.

This work was performed under the auspices of the U.S. Department of Energy at Lawrence Livermore National Laboratory under contract W-7405-ENG-48.

${ }^{1}$ Moody, K.J. "Dissolved oralloy standards and the origin of HEU," UCRL-ID-117611, (1994).

${ }^{2}$ Moody, K.J. "Determination of plutonium metal origins," UCRL-ID-120253, (1995).

${ }^{3}$ J.E. McAninch, G.S. Bench, S.P.H.T. Freeman, M.L. Roberts, J.R. Southon, J.S. Vogel and I.D. Proctor, "PXAMS - projectile X-ray AMS: X-ray yields and applications," Nuclear Instruments and Methods in Physics Research B 99, 541-545 (1995)

${ }^{4}$ I.D. Proctor, J.R. Southon, and M.L. Roberts, "Development of ${ }^{129}$ I AMS for the LLNL Spectrometer," Nuclear Instruments and Methods in Physics Research B 92, 92 (1994).

${ }^{5}$ J.E. McAninch, L.J. Hainsworth, A.A. Marchetti, M.R. Leivers, P.R. Jones, A.E.Dunlop, R. Mauthe, J.S. Vogel, I.D. Proctor, and T. Straume, "Detection of ${ }^{63} \mathrm{Ni}$ and ${ }^{59} \mathrm{Ni}$ by accelerator mass spectrometry using characteristic projectile X-rays," accepted for publication in Nuclear Instruments and Methods B as part of the Proceedings of the 7th International Conference on Accelerator Mass Spectrometry.

${ }^{6}$ M. Paul, D. Berkovits, L.D. Cecil, H. Feldstein, A. Hershkowitx, Y. Kashiv and S. Vogt, "Environmental ${ }^{90} \mathrm{Sr}$ measurements," submitted for publication in Nuclear Instruments and Methods B as part of the Proceedings of the 7th International Conference on Accelerator Mass Spectrometry. 


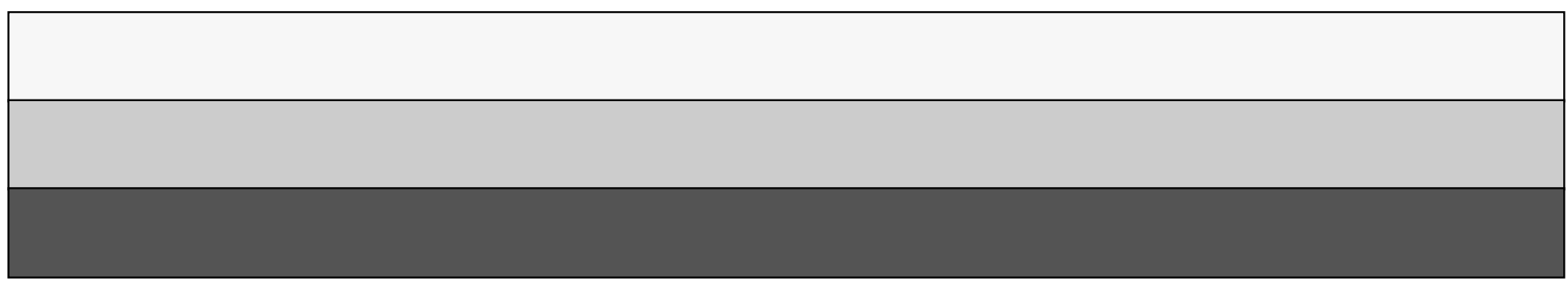

